\title{
Productivity losses associated with tuberculosis deaths in the World Health Organization African region
}

\author{
Joses Muthuri Kirigia ${ }^{1 *}$ and Rosenabi Deborah Karimi Muthuri ${ }^{2}$
}

\begin{abstract}
Background: In 2014, almost half of the global tuberculosis deaths occurred in the World Health Organization (WHO) African Region. Approximately $21.5 \%$ of the 6060742 TB cases (new and relapse) reported to the WHO in 2014 were in the African Region. The specific objective of this study was to estimate future gross domestic product (GDP) losses associated with TB deaths in the African Region for use in advocating for better strategies to prevent and control tuberculosis.

Methods: The cost-of-illness method was used to estimate non-health GDP losses associated with TB deaths. Future non-health GDP losses were discounted at $3 \%$. The analysis was conducted for three income groups of countries. One-way sensitivity analysis at 5 and $10 \%$ discount rates was undertaken to assess the impact on the expected non-health GDP loss.

Results: The 0.753 million tuberculosis deaths that occurred in the African Region in 2014 would be expected to decrease the future non-health GDP by International Dollars (Int\$) 50.4 billion. Nearly 40.8, 46.7 and 12.5\% of that loss would come from high and upper-middle- countries or lower-middle- and low-income countries, respectively. The average total non-health GDP loss would be Int\$66 872 per tuberculosis death. The average non-health GDP loss per TB death was Int $\$ 167592$ for Group 1, Int\$69 808 for Group 2 and Int\$21 513 for Group 3.

Conclusion: Tuberculosis exerts a sizeable economic burden on the economies of the WHO AFR countries. This implies the need to strongly advocate for better strategies to prevent and control tuberculosis and to help countries end the epidemic of tuberculosis by 2030, as envisioned in the United Nations General Assembly resolution on Sustainable Development Goals (SDGs).
\end{abstract}

\section{Multilingual abstracts}

Please see Additional file 1 for translations of the abstract into the six official working languages of the United Nations.

\section{Background}

The World Health Organization (WHO) estimates that the total number of deaths from tuberculosis (TB) worldwide was 1.514 million in 2014 [1]. Almost half of those deaths were from the WHO African Region. Approximately $21.5 \%$ of the $6060742 \mathrm{~TB}$ cases (new and

\footnotetext{
* Correspondence: muthurijoses@yahoo.com

${ }^{1}$ African Sustainable Development Research Consortium (ASDRC), P.O. Box 699400100 GPOKenyatta Avenue, Nairobi, Kenya

Full list of author information is available at the end of the article
}

relapse) reported to the $\mathrm{WHO}$ in 2014 were in the African Region [1].

According to the WHO, TB is intimately linked to poverty, and the control of TB is ultimately a question of justice and human rights [2]. Failure to control TB (and other poverty-related diseases) is a consequence of the significant inequities in the distribution of wealth and health care both within and between countries [36]. In the African Region, the situation is exacerbated by the relatively high incidence and prevalence of coinfection of HIV/AIDS and TB and the growing problem of mycobacterial drug resistance [7-10].

The majority of TB deaths could have been prevented if the available preventive and treatment interventions were universally accessible to all those in need. Unfortunately, the coverage of those interventions is suboptimal 
in the African Region. For example, the BCG (Bacillus Calmette-Guérin) immunisation coverage among infants (aged 1 year) is between 50 and $70 \%$ in 4 countries, $71-$ $90 \%$ in 17 countries, and $91 \%$ and above in 26 countries [11]. The case detection rate for all forms of TB was $52 \%$, and the treatment success rate for new tuberculosis cases was $81 \%$ [12]. In the absence of an effective vaccine for older ages, efforts to control the spread of $\mathrm{TB}$ will continue to rely on early diagnosis, directly observed therapy (DOTs) and public health infection control measures.

The prevention and control of $\mathrm{TB}$ is hampered by poor living conditions for vulnerable population groups and weak national health systems [12]. The national health systems lack capacities to assure universal access to $\mathrm{TB}$ prevention and control services for all those in need [13-16].

The situation calls for strong evidence-based advocacy for increased domestic and external investments into the fight against TB. One such evidence is the economic burden of TB. A retrospective cost-of-illness study in the United States estimated the 1991 direct expenditures for TB-related diagnosis and treatment to range from $\$ 515.7$ million to $\$ 934.5$ million [17]. Miller et al. estimated that in 2002, the 108 confirmed TB cases in Tarrant County (Texas, USA) cost a total of US\$40 574 953 [18]. Rajbhandary et al. estimated the mean direct cost of treating a multi-drug-resistant (MDR-TB) patient in the United States to be US\$45,000 [19].

Atun et al. estimated the mean cost of managing TB in Russia over 12 months to be US\$572 per case [20]. Fløe et al. estimated the direct cost per TB patient to be $€ 10509$ in Denmark [21]. Kik et al. estimated the direct and indirect costs of tuberculosis among immigrant patients in the Netherlands to be Euro 2956 per TB patient [22]. The Diel et al. study in Germany estimated the total cost per MDR-TB/extensively drug-resistant (XDR-TB) case to be Euro 82150 and Euro 108733 per case, respectively [23]. In another study, Diel and colleagues performed a systematic review and revealed that the average cost of treatment of MDR-TB among 15 old European Union (EU countries plus Cyprus, Malta and Slovenia to be Euro 57213 and Euro 24 166 [24]. White and Moore-Gillon estimated the mean direct cost of managing an MDR-TB patient in the United Kingdom to be $£ 60000$ [25].

The Rajeswari et al. study in India estimated the total socio-economic impact of tuberculosis on patients and their families to be US\$171 per case [26]. The Peabody et al. study in the Philippines estimated the combined economic losses due to premature tuberculosis-related mortality and morbidity to be US\$145 million [27]. The Atif et al. study in Malaysia estimated the cost of tuberculosis treatment to be US\$ 727.25 per patient [28].
The Mauch et al. study in Kenya revealed that a TB patient incurred a median direct cost of US\$55.8 and an indirect cost of US\$294.2 [29]. The Umar et al. study in Nigeria estimated the indirect cost due to pulmonary TB in patients receiving treatment to be US\$517.98 and US\$79.13 per hospitalised and non-hospitalized patient, respectively [30]. The Foster et al. study in South Africa estimated the mean total pre-treatment and treatment direct plus indirect costs incurred by respondents in accessing health care during TB diagnosis and treatment to be US\$ 324.07 [31].

Except for Peabody et al. [27], none of the other studies included the economic losses due to premature tuberculosis-related mortality. In addition, to the best of our knowledge, no study has attempted to estimate the combined economic losses due to premature tuberculosisrelated mortality for all 47 countries of the WHO African Region. Therefore, there is a dearth of evidence in the African Region on the economic burden of TB for use in advocacy for increased domestic and external investments in strengthening the national and local health systems to combat the spread of TB.

This paper attempts to answer the following question: What is the impact of TB deaths on the future nonhealth gross domestic product (GDP) in the WHO African Region? The specific objective of this study was to estimate the future GDP losses associated with TB deaths in the African Region to advocate for better strategies to prevent and control tuberculosis.

\section{Methods}

\section{Cost-of-illness framework}

Tuberculosis deaths result in future losses in the macroeconomic outputs of countries concerned with attrition of future labour and productivity, as well as an erosion of investments in human and physical capital formation [32]. In this paper, we employ a cost-of-illness model to estimate the non-health GDP losses attributable to TBrelated deaths in the African Region.

Nattrass et al. [33] defines GDP as the value of the aggregate spending on all final goods and services. GDP is the sum of the private household consumption spending on final consumer goods (e.g., food, cloth, books, detergents) and services (e.g., health, education, tourism); central, regional and local government consumption spending on salaries and wages of civil servants and goods; private and public sectors producers investment spending on additional physical stock of capital (e.g., machinery, construction, vehicles) plus changes in the total value of inventories (unsold stocks); and net exports (i.e., exports minus imports).

Private consumption is the use of goods and services to directly satisfy an individual's personal needs and wants [33]. Private consumption spending is funded 
from incomes earned by employees and self-employed people (e.g., farmers, entrepreneurs) and thus premature death of workers or self-employed people from tuberculosis (or any other cause) depletes household income and consumption. Death of those aged 0-14 years diminishes the quantity of future labour force and hence future household income and consumption.

Government consumption spending is financed largely through revenues from various forms of taxes, such as personal income tax, value-added tax, social security taxes, corporate taxes, and taxes on international trade and transactions [34]. Premature mortality due to tuberculosis (or any other cause) reduces the number of current and future tax payers and hence tax revenues available for government consumption spending and investment.

Investment spending is financed by savings, i.e., loanable funds [33, 34]. Once again, premature death from TB erodes a household's current and future income and savings needed by investors. At times, the bereaved are forced by circumstances to sell assets and spend savings to pay for funeral expenses.

Agriculture is the main source of income and employment for the $62 \%$ of the African Region population that lives in rural areas. In 2013, agriculture (including crops, forestry, hunting, and fishing, and livestock production) contributed $14.7 \%$ to the GDP of Sub-Saharan Africa. However, the contribution varies from $2.3 \%$ in South Africa to $58.2 \%$ in the Central African Republic. Of 41 countries reporting, agriculture contributed to less than $10 \%$ in 12 countries; $10-30 \%$ in 16 countries; and 31$60 \%$ in 13 countries [35]. Premature TB deaths would be expected to impact negatively on the agricultural and other sectors productivity.

According to WHO [32], the key ways through which tuberculosis deaths impact macroeconomic output include increased health expenditure, losses in labour and productivity and reduced investment in human and physical capital formation. This study uses a macroeconomic-or societal-perspective. The study's scope is limited to market economy losses (GDP), its quantity of interest is the impact of tuberculosis deaths on nonhealth components of GDP, and its estimation method is the cost-of-illness model capturing the effects across all sectors of the economy [36].

The non-health GDP loss (NHGDPLoss) associated with tuberculosis deaths in a country is the sum of the potential non-health GDP loss due to tuberculosis deaths among those aged 0-14 (NHGDPLoss ${ }_{-14}$ ), those aged 15-59 (NHGDPLoss 15-59) $_{15}$ and those aged 60 years and above (NHGDPLoss ${ }_{60 \pm}$ ). Economic losses among the three age brackets were estimated to facilitate comparisons and to avail information for use in advocacy for an increase in investments against tuberculosis, and the growing challenge of antimicrobial resistance in the region.

The non-health GDP loss associated with tuberculosis deaths among persons of a specific age group is the product of the total discounted years of life lost, per capita non-health GDP in purchasing power parity (PPP) and the total number of tuberculosis deaths. Each country's discounted total non-health GDP loss attributable to tuberculosis deaths was estimated using eqs. (1), (2), (3) and (4) presented below [37].

$$
\begin{aligned}
\text { NHGDPLoss } & \left(\text { NHGDPLoss }_{0-14}+\text { NHGDPLoss }_{15-59}\right. \\
& \left.+ \text { NHGDPLoss }_{60 \pm}\right) \\
\text { NHGDPLoss }_{0-14}= & \sum_{t=1}^{n}\left\{\left[1 /(1+r)^{t}\right] \times\left[\text { NHGDPPC }_{\text {Ints }}\right] \times\left[\text { TBD }_{0-15}\right]\right\} \\
= & \left\{\left[1 /(1+r)^{1}\right] \times\left[\text { NHGDPPC }_{\text {Ints }}\right] \times\left[\text { TBD }_{0-14}\right]\right\} \\
+ & \left\{\left[1 /(1+r)^{2}\right] \times\left[\text { NHGDPPC }_{\text {Ints }}\right] \times\left[\text { TBD }_{0-14}\right]\right\}+\ldots \\
& +\left\{\left[1 /(1+r)^{n}\right] \times\left[\text { NHGDPPC }_{\text {Ints }}\right] \times\left[\text { TBD }_{0-14}\right]\right\}
\end{aligned}
$$

$$
\begin{aligned}
\text { NHGDPLoss }_{15-59} & =\sum_{t=1}^{n}\left\{\left[1 /(1+r)^{t}\right] \times\left[\text { NHGDPPC }_{\text {Ints }}\right] \times\left[\text { TBD }_{15-59}\right]\right\} \\
& =\left\{\left[1 /(1+r)^{1}\right] \times\left[\text { NHGDPPC }_{\text {Ints }}\right] \times\left[T B D_{15-59}\right]\right\} \\
& +\left\{\left[1 /(1+r)^{2}\right] \times\left[N H G D P P C_{\text {Ints }}\right] \times\left[T B D_{15-59}\right]\right\}+\ldots \\
& +\left\{\left[1 /(1+r)^{n}\right] \times\left[N H G D P P C_{\text {Ints }}\right] \times\left[T B D_{15-59}\right]\right\}
\end{aligned}
$$

$$
\begin{aligned}
\text { NHGDPLoss }_{60 \pm} & =\sum_{t=1}^{n}\left\{\left[1 /(1+r)^{t}\right] \times\left[\text { NHGDPPC }_{\text {Ints }}\right] \times\left[\text { TBD }_{60 \pm}\right]\right\} \\
= & \left\{\left[1 /(1+r)^{1}\right] \times\left[\text { NHGDPPC }_{\text {Ints }}\right] \times\left[T^{\prime} B D_{60 \pm}\right]\right\} \\
& +\left\{\left[1 /(1+r)^{2}\right] \times\left[\text { NHGDPPC }_{\text {Ints }}\right] \times\left[\text { TBD }_{60 \pm}\right]\right\}+\ldots \\
& +\left\{\left[1 /(1+r)^{n}\right] \times\left[N H G D P P C_{\text {Ints }}\right] \times\left[T B D_{60 \pm}\right]\right\}
\end{aligned}
$$

where $1 /(1+r)^{t}$ is the discount factor; $r$ is the rate of discount of future losses; $\sum_{t=1}^{n}$ is the summation from year $t$ to $n$; $t$ is the first year of life lost, and $n$ is the final year of the total number of years of life lost per tuberculosis death, which is obtained by subtracting the average age at death (AAD) for tuberculosis-related causes from each country's average life expectancy at birth. NHGDPPC $C_{\text {Int } \$}$ 
is the per capita non-health gross domestic product in purchasing power parity (PPP), which is obtained by subtracting the per capita total health expenditure (PCTHE) from the per capita GDP $\left(G D P P C_{I n t \$}\right) . T B D_{0-14}$ is the total tuberculosis deaths between the ages of $0-14$ years in country $k$ in 2013; $T B D_{15-59}$ is the total tuberculosis deaths between the age of 15-59 years in country $k$ in 2013; and $T B D_{60 \pm}$ is the total tuberculosis deaths for ages 60 years and above in country $k$ in 2013. We used 2013 as the base year to which losses occurring in future years were discounted. As explained by Kirigia [38], Drummond et al. [39] and Curry and Weiss [40], the discount factor applied to the GDP losses of different years then depends on both the discount rate $(r)$ and the number of years $(t)$ over which the discounting is conducted.

The non-health GDP per capita in purchasing power parity for each of the 47 countries in the WHO African Region was calculated by subtracting the per capita total health expenditure from the per capita GDP.

\section{Illustration of calculation of loss in total non-health GDP}

The example below presents a calculation of the tuberculosis death-related loss in non-health GDP using the actual information on Nigeria:

(a) Total tuberculosis deaths in Nigeria in 2014 $=250000$

(b)Proportion of deaths among those aged 0-14 years $=0.125255548607164$

(c) Proportion of deaths among those aged 15-59 years $=0.774170807391794$

(d) Proportion of deaths among those aged $60+$ years $=$ 0.100573644001042

(e) $T B D_{0-14}=250000 \times 0.125255548607164=$ 31313.887151791

(f) $T M D_{15-59}=250000 \times 0.774170807391794=$ 193542.701847949

(g) $T M D_{60+}=250000 \times 0.100573644001042=$ 25143.4110002605

(h)Average age at death among those aged 0-14 years $\left(A A D_{0-14}\right)$, i.e., $(0+14) / 2=7$ years

(i) Number of years needed, in addition to $A A D_{0-14}$, to reach the legal minimum age for employment of 15 years $\left(A g e_{0}-14\right.$ Min $)$, i.e., 7 years.

(j) Average age at death among those aged $15-59$ years $\left(A A D_{15}-59\right)$, i.e., $(15+59) / 2=37$ years

(k) Average age at death among those aged 60 years and older $\left(A A D_{60 \pm}\right)$, i.e., 60 years

(l) Nigeria's average life expectancy at birth (LE) $=55$ years

(m)Per capita gross domestic product $\left(G D P P C_{\text {Int\$ }}\right)=$ Int $\$ 5756.271$

(n)Per capita total expenditure on health $(P C T H E)=$ Int $\$ 207$

(o) NHGDPPC $=G D P P C_{\text {Int } \$}-P C T H E=\operatorname{Int} \$ 5756.271-$ Int $\$ 207=$ Int $\$ 5550$
(p)Discount rate $(r)=3 \%$

(q)Undiscounted years of life lost in the group aged $0-14$ years $\left(Y L L_{0-14}\right)=L E-\left(A A D_{0-14}+A g e_{0}\right.$ 14 Min $)=55-(7+7)=41$ years

(r) Discounted years of life lost in the group aged 0-14 years $\left(D Y L L_{0-14}\right)=23.4123999749577$

(s) Undiscounted years of life lost in the group aged $15-59$ years $\left(Y L L_{15-59}\right)=L E-A A D_{15-59}=$ $55-37=18$ years

(t) Discounted years of life lost in the group aged 15-59 years $\left(D Y L L_{15-59}\right)=13.7535130794572$

(u) Undiscounted years of life lost in the group aged 60 + years $\left(Y L L 6_{60 \pm}\right)=L E-A A D_{60 \pm}=0$ (because the Nigeria average LE of 55 years is less than 60 years, we assumed that years of life lost within this age group are zero. However, this assumption is adjusted in the sensitivity analysis where we re-estimate the model using highest life expectancy in the region, i.e., 75 years in Cape Verde).

(v) Discounted years of life lost in the group aged 60+ years $\left(D Y L L_{60+}\right)$ equals zero for reason explained in ' $\mathrm{t}$ ' above.

(w) NHGDPLoss ${ }_{0-14}={\text { Discounted } Y L L_{0-15} \times}$ NHGDPPC ${ }_{\text {Int } \$} \times T B D_{0-14}=23.4123999749577 \times$ $5550 \times 31313.887151791=\operatorname{Int} \$ 4068889541.76473$

(x)NHGDPLoss ${ }_{15-59}=$ Discounted $Y L L_{15-59} \times$ NHGDPPC $C_{\text {Int } \$} \times T_{B D D_{15-59}}=13.7535130794572 \times$ $5550 \times 193542.701847949=$ Int\$14 773501051.2108

(y) NHGDPLoss $60 \pm=$ Discounted $Y L L_{60 \pm} \times$ NHGDPPC Int\$ $\times T B D_{60 \pm}=0 \times 5550 \times 25143.4110002605=\operatorname{Int} \$ 0$.

(z) NHGDPLoss $=\left(\right.$ NHGDPLoss $_{0}-14+$ NHGDPLoss $_{15}-$ $59+$ NHGDPLoss $\left._{60 \pm}\right)=\operatorname{Int} \$ 4068889541.76473+$ Int $\$ 14773501051.2108+\operatorname{Int} \$ 0=\operatorname{Int} \$ 18842$ 390592.9755.

\section{Sensitivity analysis}

A discount rate of $3 \%$ was used because it is commonly used in cost-of-illness studies [41, 42], burden of disease studies $[43,44]$ and WHO health systems' performance assessment [45]. However, a one-way sensitivity analysis was conducted at 5 and $10 \%$ discount rates to test the effect of the discount rate on the overall total expected non-health GDP loss estimate.

The study used 7 years (a simple average) as the average age at death for the 0-14 age bracket; 37 years for the 15-59 age bracket; and 60 years for the 60 years and above. Because the legal minimum working age limit is 15 years [46], we considered only the years above 14 years when calculating the productive years of life lost for the 0-14 age bracket. A sensitivity analysis was conducted to determine the effect of age on the overall total non-health GDP loss estimate. The model was reestimated assuming an average age at death of 0 years for the 0-14 age bracket; an average age at death of 
Table 1 Economic classification of WHO African Region Countries in 2013

\begin{tabular}{lll}
\hline Group & GNI per capita (US\$) & Countries \\
\hline Group 1: High income and upper-middle income & $>=4086$ & $\begin{array}{l}\text { Algeria, Angola, Botswana, Equatorial Guinea, Gabon, Mauritius, Namibia, } \\
\text { Seychelles, South Africa (9) }\end{array}$ \\
Group 2: Lower-middle income & $1036-4085$ & $\begin{array}{l}\text { Cameroon, Cape Verde, Congo, Cote d'Ivoire, Ghana, Kenya, Lesotho, } \\
\text { Mauritania, Nigeria, São Tome and Principe, Senegal, Swaziland, Zambia (13) }\end{array}$ \\
& \multirow{2}{*}{$\begin{array}{l}1035 \text { or less } \\
\text { Group 3: Low income }\end{array}$} & $\begin{array}{l}\text { Benin, Burkina Faso, Burundi, Central African Republic, Chad, Comoros, } \\
\text { DRC, Eritrea, Ethiopia, The Gambia, Guinea, Guinea-Bissau, Liberia, }\end{array}$ \\
& $\begin{array}{l}\text { Madagascar, Malawi, Mali, Mozambique, Niger, Rwanda, Sierra Leone, } \\
\text { South Sudan, Tanzania, Togo, Uganda, Zimbabwe (25) }\end{array}$ \\
\hline
\end{tabular}

15 years for the 15-59 age bracket; and each country's average life expectancy as the average age at death for the age bracket of 60 years and above, while simultaneously assuming the African Region's maximum life expectancy of 75 years (i.e., life expectancy for Cape Verde).

\section{Data sources and analysis}

The data used to estimate eqs. 1, 2, 3 and 4 were obtained from following sources: the life expectancy at birth data were taken from WHO World Health Statistics 2015 [12]; the proportions of deaths occurring in the three age groups were from the WHO mortality and burden of disease estimates for WHO member states in 2008 [43]; the total tuberculosis deaths were taken from the WHO World Tuberculosis Report 2015 [1]; the per capita gross domestic product in purchasing power parity (PPP) values were from the International Monetary Fund database [47]; and per capita total health expenditure data were from the World Health Statistics 2015 [12].

The formulas in eqs. (1), (2), (3) and (4) were used to estimate the non-health GDP losses and were built in an Excel spreadsheet. For the analysis, the countries were organised into three economic groups, as shown in Table 1, with high- and upper-middle-income countries in Group 1, lower-middle-income countries in Group 2 and low-income countries in Group 3. A calculation for the countries by income group was meant to facilitate comparisons.

\section{Ethical clearance}

The study did not require WHO/AFRO Ethics Review Committee approval because it did not involve human subjects. It relied entirely on data from published sources.

\section{Results}

Table 2 presents the WHO African Region's population and tuberculosis deaths by economic group in 2014. Of the total of 753423 tuberculosis deaths that occurred, $16.26 \%$ belonged to the high- and upper-middle-income countries (Group 1), $44.73 \%$ to the lower-middleincome countries (Group 2) and $39.01 \%$ to the lowincome countries (Group 1).

\section{Non-health GDP loss attributable to tuberculosis deaths}

The 0.753 million tuberculosis deaths that occurred in the African Region in 2014 would be expected to decrease future non-health GDP by Int $\$ 50,382,574,953$ (Table 3 ). Nearly $40.8 \%$ of the loss would be represented by Group 1 countries, $46.7 \%$ by group 2 and $12.5 \%$ by group 3. The interquartile range of the median GDP loss by country is Int $\$ 440,387,653$. The potential loss of future discounted non-health GDP would vary widely, from Int\$0 in Seychelles to Int\$18.84 billion in Nigeria.

\section{Non-health GDP loss in Group 1 countries}

The 122526 TB deaths in Group 1 countries are expected to result in a total loss of Int\$20 534 328490 in non-health GDP in 2013, which is equivalent to $1.36 \%$ of the group's total GDP. The total productivity loss varied importantly, from Int $\$ 0$ in Seychelles to Int $\$ 16.6$ billion in South Africa. Figure 1 displays the distribution of the total non-health GDP across the nine high and upper-middle income countries in Group 1. Approximately $81 \%$ of the expected loss in Group 1 was represented by South Africa.

Table 2 Population and tuberculosis deaths by economic group in WHO African Region countries

\begin{tabular}{lll}
\hline Group/economic class & (A) Population in 2013 & (B) Tuberculosis Deaths in 2014 \\
\hline Group 1: High income \& upper-middle income & 121546000 & 122526 \\
Group 2: Lower-middle income & 331470000 & 337009 \\
Group 3: Low income & 478356000 & 293888 \\
TOTAL & 931372000 & 753423 \\
\hline
\end{tabular}

Source: WHO $[1,12]$ 
Table 3 Discounted values of future non-health GDP losses from tuberculosis deaths among WHO African Region countries in 2014 (2013, Int\$ or PPP)

\begin{tabular}{|c|c|c|}
\hline Countries & International Dollars (PPP) & Percentage \\
\hline Algeria & 1245265365 & 2.47 \\
\hline Angola & 1283658670 & 2.55 \\
\hline Benin & 36750328 & 0.07 \\
\hline Botswana & 405550047 & 0.80 \\
\hline Burkina Faso & 52205284 & 0.10 \\
\hline Burundi & 42896468 & 0.09 \\
\hline Cameroon & 671947468 & 1.33 \\
\hline Cape Verde & 23398102 & 0.05 \\
\hline Central African Republic & 36287667 & 0.07 \\
\hline Chad & 160379659 & 0.32 \\
\hline Comoros & 1492351 & 0.00 \\
\hline Congo & 432543715 & 0.86 \\
\hline Cote D'Ivoire & 229438028 & 0.46 \\
\hline DRC & 426514828 & 0.85 \\
\hline Equatorial Guinea & 64069641 & 0.13 \\
\hline Eritrea & 18720135 & 0.04 \\
\hline Ethiopia & 870327842 & 1.73 \\
\hline Gabon & 392992668 & 0.78 \\
\hline Gambia & 12332470 & 0.02 \\
\hline Ghana & 934667549 & 1.86 \\
\hline Guinea & 87848382 & 0.17 \\
\hline Guinea-Bissau & 44826660 & 0.09 \\
\hline Kenya & 870294829 & 1.73 \\
\hline Lesotho & 149807038 & 0.30 \\
\hline Liberia & 43220969 & 0.09 \\
\hline Madagascar & 301036739 & 0.60 \\
\hline Malawi & 140425230 & 0.28 \\
\hline Mali & 44430032 & 0.09 \\
\hline Mauritania & 61852822 & 0.12 \\
\hline Mauritius & 8191726 & 0.02 \\
\hline Mozambique & 719984725 & 1.43 \\
\hline Namibia & 501033284 & 0.99 \\
\hline Niger & 54836009 & 0.11 \\
\hline Nigeria & 18841273630 & 37.40 \\
\hline Rwanda & 25108682 & 0.05 \\
\hline Sao Tome \& Principe & 1007272 & 0.00 \\
\hline Senegal & 131075954 & 0.26 \\
\hline Seychelles & - & 0.00 \\
\hline Sierra Leone & 46928838 & 0.09 \\
\hline South Africa & 16633567089 & 33.01 \\
\hline South Sudan & 119338372 & 0.24 \\
\hline Swaziland & 233669870 & 0.46 \\
\hline
\end{tabular}

Table 3 Discounted values of future non-health GDP losses from tuberculosis deaths among WHO African Region countries in 2014 (2013, Int\$ or PPP) (Continued)

\begin{tabular}{llr}
\hline Tanzania & 2538873431 & 5.04 \\
Togo & 17528131 & 0.03 \\
Uganda & 289994353 & 0.58 \\
Zambia & 944859661 & 1.88 \\
Zimbabwe & 190122940 & 0.38 \\
Total loss (Int\$) & 50382574953 & 100.00 \\
\hline
\end{tabular}

\section{Non-health GDP loss in Group 2 countries}

The 337009 TB deaths in Group 2 countries resulted in an expected total loss of Int\$23 525835936 in nonhealth GDP, or $1.6 \%$ of the group's total GDP. The loss was wide-ranging, from Int\$1 007272 in São Tomé and Príncipe to Int\$18 841273630 in Nigeria. Figure 2 presents the distribution of the total non-health GDP loss across the 13 lower-middle income countries in Group 2. Approximately $80.1 \%$ of the loss in Group 2 was represented by Nigeria.

\section{Non-health GDP loss in Group 3 countries}

The 293888 TB deaths that occurred among Group 3 countries in 2013 resulted in a total expected loss in non-health GDP of Int\$6 322410 528, which is equivalent to $0.91 \%$ of the group's total GDP. The expected loss varied from Int $\$ 1.5$ million in Comoros to Int $\$ 2.54$ billion in Tanzania. Figure 3 shows the distribution of the total non-health GDP loss across the 25 low-income countries in Group 3. The Democratic Republic of the Congo (DRC), Ethiopia, Madagascar, Mozambique and Tanzania collectively incurred $76.8 \%$ of the expected loss in this group. In spite of the fact that Group 3 TB deaths were 2.4 times those of Group 1, the non-health GDP loss of Group 1 was 3.2 times higher than that of Group 3 because Group 1 had a higher per capita GDP.

\section{Average non-health GDP losses}

Table 4 shows the average non-health GDP losses per TB death and per person in population for the 47 countries. The average non-health GDP lost per TB death was Int $\$ 167,592$ for Group 1, Int\$69 808 for Group 2 and Int $\$ 21,513$ for Group 3. The average non-health GDP loss per person in the population was Int $\$ 168.9$ for Group 1, Int $\$ 71$ for group 2 and Int\$13.2 for Group 3. The average non-health GDP lost per TB death was slightly more than two times that for Group 2 and about eight times that for Group 3.

\section{Sensitivity analysis}

Employing a $5 \%$ discount rate reduced the total expected non-health GDP loss by Int $\$ 9.703$ billion 


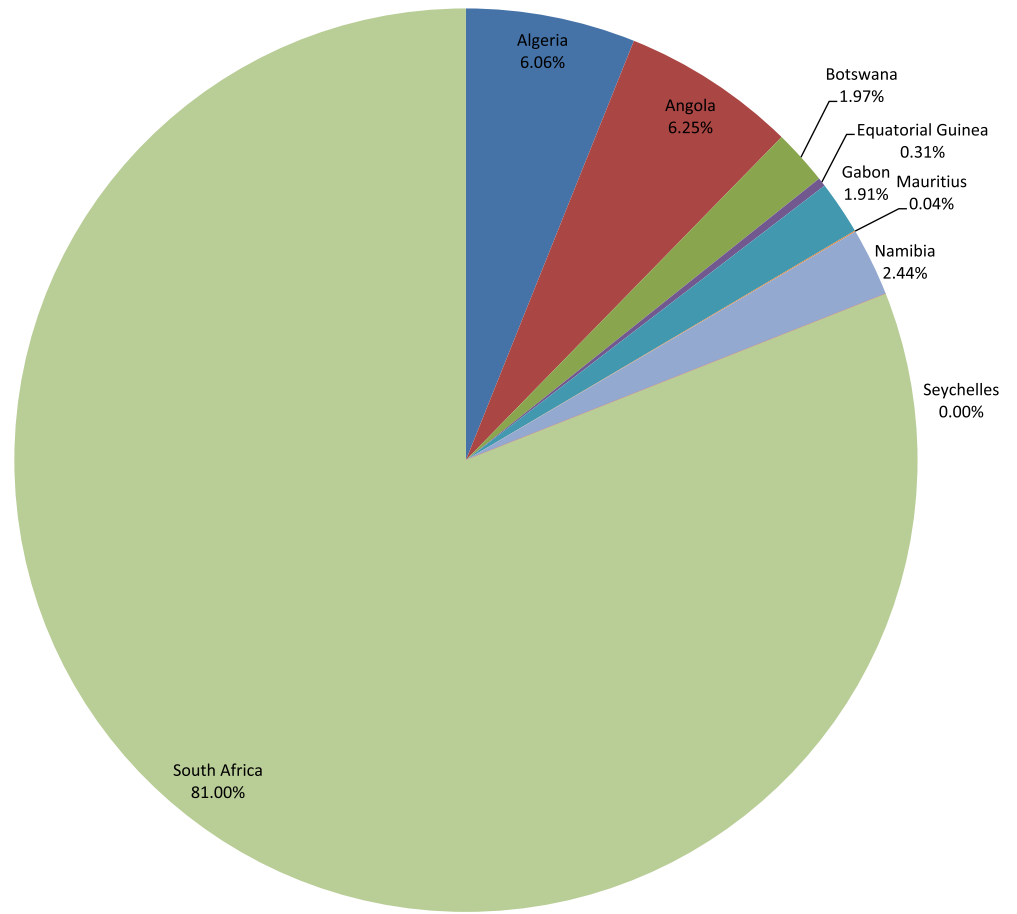

Fig. 1 Non-health GDP loss in Group 1 due to tuberculosis deaths in high-income and upper-middle- income countries of the WHO African Region, 2013

(19.26\%) and the average non-health cost per TB death by Int $\$ 12878$. Whereas, application of a $10 \%$ discount rate reduced the overall total non-health GDP loss by Int\$23 851884140 (47.34\%) and the average nonhealth GDP loss per TB death by Int\$31 658 .

The use of the average age at death of 0 years for the 0-14 age bracket; 15 years for the 15-59 age bracket; and each country's average life expectancy as the average age at death for the age bracket of 60 years and above, while simultaneously assuming the region's maximum life expectancy of 75 years, raised the total non-health GDP loss by Int $\$ 28.4$ billion, which is a $56.3 \%$ increase. This also increased the average non-health GDP loss per TB deaths by Int $\$ 37,649$. Because the non-health GDP loss also seems to partially depend on the average age used for the onset of $\mathrm{TB}$ deaths, there is a need for epidemiological research into the age distribution of TB deaths.

\section{Discussion}

The estimated total expected non-health GDP loss ascribed to TB deaths of Int $\$ 50.4$ billion is approximately $1.37 \%$ of the collective GDP of the 47 WHO African Region member states. This estimate signifies the expected loss in potential GDP in the future from the $753,423 \mathrm{~TB}$ deaths, which is revalued relative to the base year of 2013. The sensitivity analysis revealed that the size of the total non-health GDP loss partially depends on the discount rate used and the average age used for the onset of TB deaths. The latter implies that there is a need for epidemiological research into the age distribution of TB deaths.

The Group 3 (low income) countries are the home of $51.4 \%$ of the African Region population, incurred $39 \%$ of TB deaths, and bore only $12.5 \%$ of non-health GDP losses associated with TB deaths in the region. On the other hand, even though Group 1 (high income and upper-middle income) countries have only $13.1 \%$ of the regional population and incurred only $16.3 \%$ of TB deaths (probably due to better living and working conditions), it bore $40.8 \%$ of the non-health GDP losses associated with TB in the region. This is attributed to the fact that the Group 1 per capita income of Int\$9,257 is eight times higher than that of Group 3 countries of Int $\$ 1,131$. This implies that even though the TB disease burden is lower in Group 1 vis-a-vis Group 3, it should not be a reason for complacency because the negative impact on Group 1 economies is quite sizeable.

As mentioned in the Background, there is a worldwide paucity of studies that estimate the economic losses due to premature mortality from TB. Peabody et al. estimated the combined annual income loss due to TB morbidity and premature mortality to be US\$145 million in the Philippines in 1997, of which US\$32 million (22.1\%) was 


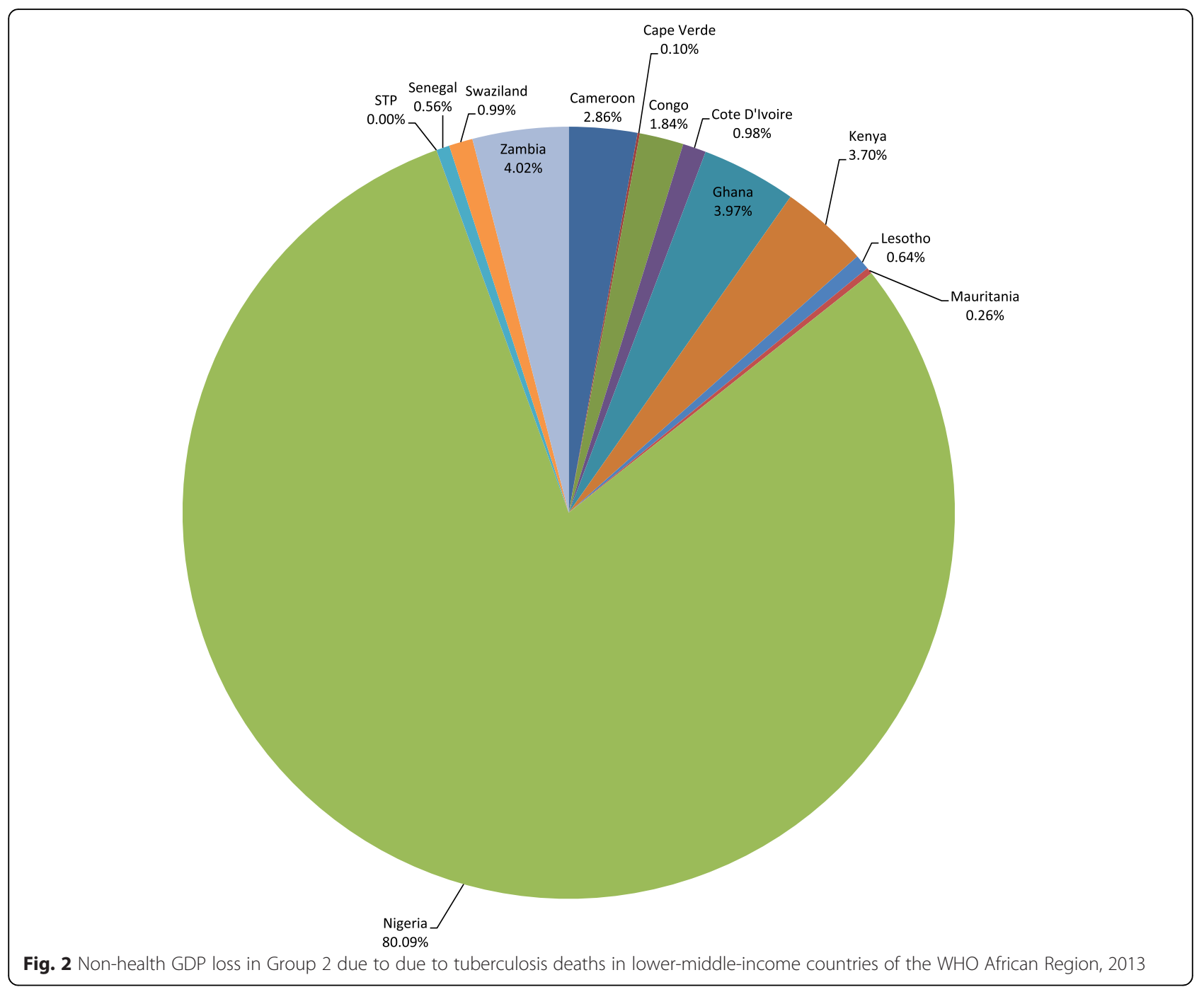

attributed to premature mortality [27]. Hickson estimated the magnitude of the decline in the mortality and morbidity burden of TB at 104,425 life years, valued at US $\$ 127$ billion in England and Wales. Out of the latter loss, \$71 billion (55.9 \%) was attributed to TB mortality [48]. The median GDP loss per country in the African Region was Int\$140.4 million in 2013, which confirms that premature mortality from TB lowers a country's GDP.

Cognizant of the correlation between health and economic development, the UN General Assembly in 2015 adopted a development agenda whose sustainable development goal (SDG) 3 focuses on ensuring healthy lives and promoting well-being for all people at all ages [49]. Target 3.3 focuses on ending the epidemics of AIDS, tuberculosis, malaria and neglected tropical diseases and combating hepatitis, water-borne diseases and other communicable diseases by 2030. The Sixty-Seventh World Health Assembly resolution, WHA67.1, adopted the global strategy and targets for TB prevention, care and control after 2015 [50]. The strategy provides detailed guidance to member states on key interventions for eliminating TB by 2035; some of which include the following: early diagnosis and treatment using DOTS; treatment of all people with multi-drug-resistant TB; and antiretroviral therapy for HIV-positive TB patients with tuberculosis/HIV activities [51].

One may ask whether those interventions are economically viable. Korenromp et al. [52] projected that in the African Region, the cost of diagnosing and treating one TB patient under DOTS would be US\$503, with an additional cost incurred if the patient has multi-drug resistance (MDR) TB that would be US \$4 315. Other additional costs would be incurred if the patent is HIVpositive and receives antiretroviral therapy (ART) for the duration of a 6-month DOTS course, which would be US\$236 in 2010. As shown in Table 5, if we inflate those 


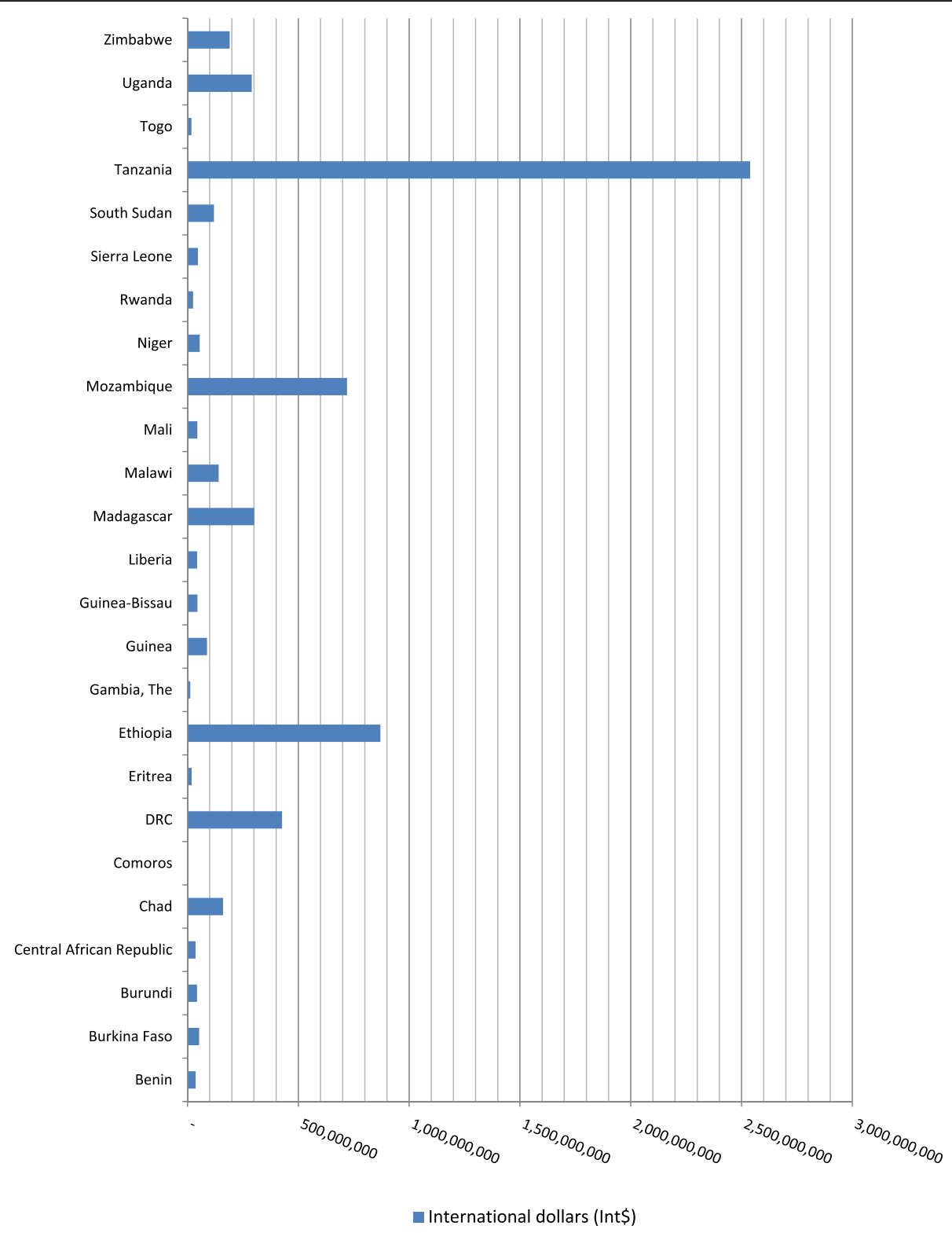

Fig. 3 Non-health GDP loss in Group 3 due to tuberculosis deaths in low-income countries of the WHO African Region, 2013

2010 costs by $3 \%$ per year over a period of 3 years (to 2013) and sum them, then we obtain a total cost of US\$1 975738 381, which when discounted at $3 \%$ comes to \$1 918192 602. Dividing the GDP loss (which is potential savings) of $\$ 50.4$ billion by the cost of $\mathrm{TB}$ interventions ( $\$ 1.92$ billion) yields a benefit-cost ratio (BCR) of 26.2. This means that policymakers can expect $\$ 26.2$ in benefits for every $\$ 1$ invested in the three TB interventions. Therefore, since the BCR is greater than 1 , this means the benefits outweigh the costs and the

Table 4 Discounted values of future non-health GDP lost due to TB deaths in 2014 by economic group (in 2013 international dollars)

\begin{tabular}{|c|c|c|c|c|}
\hline Cost item & Group 1 (Int\$) & Group 2 (Int\$) & Group 3 (Int\$) & Grand total Cost (Int\$) \\
\hline Total cost of TB deaths & 20534328490 & 23525835936 & 6322410528 & 50382574953 \\
\hline Average cost per TB death & 167592 & 69808 & 21513 & 66872 \\
\hline Average cost per person in population & 168.9 & 71.0 & 13.2 & 54.1 \\
\hline$\%$ of Grand Total & 40.8 & 46.7 & 12.5 & 100 \\
\hline
\end{tabular}


Table 5 Total cost of TB interventions and the benefit-cost ratio for the African Region

\begin{tabular}{|c|c|c|c|}
\hline Variables & Number of TB cases $^{\mathrm{a}}$ & Cost per TB patient $(\$)^{b}$ & Sub-Total Cost (\$) \\
\hline TB Incidence (including HIV) & 2700000 & 549.6417 & 1484032538.70 \\
\hline TB Incidence (HIV-positive) & 870000 & 257.8836 & 224358707.64 \\
\hline MDR-TB & 56700.00 & 4715.117 & 267347134.18 \\
\hline Undiscounted total cost (USD) & & & 1975738381 \\
\hline (A). Discounted total cost (Int\$) at a $3 \%$ rate & & & 1918192602.45 \\
\hline (B). GDP Loss (potential saving) & & & 50382574953 \\
\hline Benefit/cost ratio, i.e., (B)/(A) & & & 26.2656497 \\
\hline
\end{tabular}

Source: ${ }^{\mathrm{W}} \mathrm{WHO}[1]$; ${ }^{\mathrm{b}}$ Korenromp et al. [52]

investment into the three interventions for TB patients should be considered worthwhile.

The sizeable economic losses attributable to premature TB-related mortality imply an urgent need for governments (in collaboration with the Regional Economic Communities, the private sector, the civil society, Global Health Initiatives and development partners) to fully implement the global End TB Strategy to eliminate premature mortality from TB. The full implementation of the strategy to curb the TB disease burden and attenuate the related economic losses has high-level political support contained in the decisions and resolutions on TB from the Organization of African Unity/African Union [53-56], the WHO Regional Committee for Africa [57-60], the World Health Assembly [50, 61-64] and the United Nations General Assembly [65, 66].

\section{Limitations of the study}

This study has a number of limitations. First, it focuses only on the effects that TB-related premature mortality has on the economy. It does not include the cost of absence from work and reduced labour performance/productivity due to prolonged periods of sickness. We omitted direct costs, including health care cost of treating ordinary TB cases and those resulting from longer hospital stays for individuals with resistant infections, e.g., MDR-TB and XDR-TB.

Second, the GDP per capita gives no indication about how available resources are distributed across people and households. For instance, the average income per capita might remain unchanged while the distribution of income changes, which has implications for the typical household [67].

Third, the GDP only captures economic activities associated with market transactions. Its calculation omits the value of full-time homemakers (domestic labour). For example, the value of labour of women who choose to stay at home doing house work and raising children is omitted [68].

Fourth, GDP does not include the cost of production or consumption processes externalities such as pollution, environmental degradation and costs of substance abuse (e.g., alcohol, smoking) [68].

Finally, loss of human life due to tuberculosis has an effect on the well-being of the bereaved family members that goes well beyond the loss of incomes to which it gives rise [69]. Some of that effect includes psychological pain of losing a loved one; the stress and anxiety of losing a caretaker or a breadwinner; and negative impact on the children's nutrition status and education when a parent dies.

\section{Conclusion}

This paper sought to contribute to the literature on the economic burden of TB. The 47 WHO African Region Member States lost 1.37 \% of their combined GDP due to the $753423 \mathrm{~TB}$ deaths in 2014. That is a sizeable loss in a Region where $47 \%$ of the population lives on less than one international dollar per day [12]. Approximately $75.86 \%$ of the loss was represented by those aged 15-59 years, which is the most productive age bracket.

The fact that a premature mortality resulting from $\mathrm{TB}$ lowers the GDP implies that the governments of African countries in collaboration with the Regional Economic Communities, private sector, the civil society, Global Health Initiatives and development partners ought to support full implementation of the Global End TB Strategy.

The economic evidence contained in this paper is only one argument for the universal coverage of public health interventions to end morbidity and premature mortality from TB. The literature is replete with other arguments such as the contagious nature of $\mathrm{TB}$ and its threat to global health security [70], the growing burden of MDR-TB and XDR-TB [1, 71], comorbidity of HIV and TB [72], sub-optimal performance of national TB programmes [73] and human rights (social justice) considerations [74].

\section{Additional file}

Additional file 1: Multilingual abstract in the six official working languages of the United Nations (PDF $330 \mathrm{~kb}$ ) 


\section{Abbreviations}

$A A D$ : average age at death; $A A D=>60$ : average age at death for those aged 60 years and above; AAD0-14: average age at death for those aged 0-14 years; AAD 15-59: average age at death for those aged 15-59 years; DOTS: directly observed treatment, short-course; DYLL: discounted years of life lost; $D Y L L_{ \pm 60}$ : discounted years of life lost in the group aged 60 years; DYLL 0 -14: discounted years of life lost in the group aged 0-14 years; DYLL $15-59$ : discounted years of life lost in the group aged 15-59 years; GDP: gross domestic product; GDPPC Ints: Per capita GDP in international dollars; Int\$: international dollars; LE: life expectancy at birth; MDR-TB: multi-drug-resistant TB; N: final year of the total number of years of life lost per death associated with TB; NHGDPC Ints: per capita non-health GDP in PPP; NHGDPLoss: non-health GDP loss; NHGDPLoss $=>60$ : non-health GDP loss in the 60 years and above age group; NHGDPLoss $0-14$ : non-health GDP loss in the 0-14 age group: NHGDPLoss $15-5$ : non-health GDP loss in the 15-59 age group; PCTHE: per capita total health expenditure; PPP: purchasing power parity; PYLL: productive years of life lost; R: rate of discount of future losses; SDG: sustainable development goals; t: first year of life lost; TB: tuberculosis; TBD: total number of deaths associated with $\mathrm{TB}_{\mathrm{i}} \mathrm{TBD}_{0-14}$ : total tuberculosis deaths associated with TB in the 0-14 age group; $\mathrm{TBD}_{15-59}$ : total tuberculosis deaths associated with TB in the 15-59 age group; TBD $_{60 \pm}$ : total tuberculosis deaths associated with TB in the 60 years and above age group; WHO: World Health Organization; XDR-TB: extensively drug-resistant TB; YLL 014 : undiscounted years of life lost in the group aged 0-14 years; $Y L_{15-59}$ : undiscounted years of life lost in the group aged 15-59 years; $Y L L_{ \pm 60}$ : undiscounted years of life lost in the group aged 60 years and above.

\section{Competing interests}

The authors declare that they have no competing interests.

\section{Authors' contributions}

JMK and RDKM contributed to the study design, analysis of the data and the writing of the manuscript. Both authors read and approved the final paper.

\section{Authors' information}

Joses M. Kirigia holds a PhD in Economics (health economics specialisation) from the University of York, United Kingdom; a post-graduate Diploma in Health Economics from the University of Tromso, Norway; and a MA Degree in Economics from the University of Nairobi, Kenya. He did his PhD studies with a training grant from the United Nations Special Programme for Research and Training in Tropical Diseases (TDR). Over the past 17 years, he has worked with the WHO Regional Office for Africa (WHO/AFRO) in various capacities. He is currently the Programme Manager for Research, Publications and Library Services at the WHO/AFRO. He will be retiring from WHO on $30^{\text {th }}$ April 2016. Prior to joining the WHO, he was a senior lecturer and coordinator of the Masters in Health Economics Programme at the University of Cape Town, South Africa. He has published more than 100 articles in peer-reviewed journals; and has published, with the University of Nairobi, two books entitled 'Economic evaluation of public health problems in sub-Saharan Africa' and 'Efficiency of health system units in Africa: a data envelopment analysis'. Rosenabi D.K. Muthuri (RDKM) is currently finalising her Bachelor of Art Degree in Psychology at the United States International University (USIU), Nairobi, Kenya. She has worked as a research assistant in a number of research projects and has published three peer-reviewed articles. She has been accepted to study a Master of Science Degree at the University of Nottingham, UK.

\section{Acknowledgements}

Jehovah-Shalom gave us peace in the process of writing this manuscript. This manuscript contains the views of the authors only and does not represent the views or policies of the institutions or organisations for which they work (or are affiliated with).

\section{Author details}

${ }^{1}$ African Sustainable Development Research Consortium (ASDRC), P.O. Box 699400100 GPOKenyatta Avenue, Nairobi, Kenya. ${ }^{2}$ Department of Psychology, School of Social Sciences and Humanities, United States International University, Nairobi, Kenya.

Received: 20 February 2016 Accepted: 21 April 2016 Published online: 01 June 2016

\section{References}

1. World Health Organization (WHO). Global tuberculosis report 2015. Geneva: WHO; 2015.

2. WHO. BCG vaccine - WHO position paper. Wkly Epidemiol Rec. 2004;4(79): 27-38.

3. Oxlade O, Murray M. Tuberculosis and Poverty: Why Are the Poor at Greater Risk in India? PLoS One. 2012;7(11):e47533. doi:10.1371/journal.pone. 0047533.

4. Boccia D, Hargreaves J, Ayles H, Fielding K, Simwinga M, Godfrey-Faussett P. Tuberculosis infection in Zambia: the association with relative wealth. Am J Trop Med Hyg. 2009;80(6):1004-11.

5. Suk JE, Manissero D, Büscher G, Semenza JC. Wealth Inequality and Tuberculosis Elimination in Europe. Emerg Infect Dis. 2009;15(11):1812-4.

6. WHO Regional Office for Europe. How health systems can address inequities in priority public health conditions: the example of tuberculosis. Copenhagen: WHO Regional Office for Europe; 2010.

7. $\quad$ Dheda K, Barry CE, Maartens G. Tuberculosis. Lancet. 2016;387(10024):121126. doi:10.1016/S0140-6736(15)00151-8.

8. WHO. Multidrug-resistant tuberculosis (MDR-TB) 2014 update. Geneva: WHO; 2014.

9. Dheda K, Gumbo T, Gandhi NR, Murray M, Theron G, Udwadia Z, Migliori GB, Warren R. Global control of tuberculosis: from extensively drug-resistant to untreatable tuberculosis. Lancet Respir Med. 2014;2(4):321-38.

10. Lönnroth K, Castro KG, Chakaya JM, Chauhan LS, Floyd K, Glaziou P, Raviglione MC. Tuberculosis control and elimination 2010-50: cure, care, and social development. Lancet. 2010;375:1814-29.

11. WHO. WHO vaccine-preventable diseases: monitoring system 2015 global summary. Geneva: WHO; 2016.

12. WHO. World Health Statistics 2015. Geneva: WHO; 2015.

13. Taskforce on Innovative International Financing for Health Systems. More Money for Health, and More Health for the Money: Final Report. Geneva: International Health Partnership; 2009.

14. WHO. World Health Report 2010 - Health systems financing: the path to universal coverage. Geneva: WHO; 2010.

15. WHO website. Global Health Observatory, Geneva. URL: http://www.who.int/ gho/health_financing/en/Accessed on 1st August 2015 at 23 h00

16. Sambo LG, Kirigia JM. Investing in health systems for universal health coverage in Africa. BMC Int Health Hum Rights. 2014;14:28. doi:10.1186/ s12914-014-0028-5.

17. Brown RE, Miller B, Taylor WR, Palmer C, Bosco L, Nicola RM, Zelinger J, Simpson K. Health-care expenditures for tuberculosis in the United States. Arch Intern Med. 1995;155(15):1595-600.

18. Miller TL, Mcnabb SJN, Hilsenrath P, Pasipanodya J, Drewyer G, Weis SE. The Societal Cost of Tuberculosis: Tarrant County, Texas, 2002. Ann Epidemiol. 2010;20(1):1-7. doi:10.1016/j.annepidem.2009.09.004.

19. Rajbhandary SS, Marks SM, Bock NN. Costs of patients hospitalized for multidrug-resistant tuberculosis. Int J Tuberc Lung Dis. 2004;8(8):1012-6.

20. Atun R, Samyshkin Y, Drobniewski F, Balabanova Y, Fedorin IM, Lord J, Coker RJ. Costs and outcomes of tuberculosis control in the Russian Federation: retrospective cohort analysis. Health Policy Plan. 2006;21(5):353-64.

21. Fløe A, Hilberg O, Wejse C, Løkke A, Ibsen R, Kjellberg J, Jennum P. The economic burden of Tuberculosis in Denmark 1998-2010. Cost analysis in patients and their spouses. Int J Infect Dis. 2015;32:183-90.

22. Kik SV, Olthof SPJ, Vries JTN, Menzies D, Kincler N, Loenhout-Rooyakkers J, Burdo C, Verver S. Direct and indirect costs of tuberculosis among immigrant patients in the Netherlands. BMC Public Health. 2009;9:283. doi: 10.1186/1471-2458-9-283.

23. Diel R, Nienhaus A, Lampenius N, Rusch-Gerdes S, Richter E. Cost of multi drug resistance tuberculosis in Germany. Respir Med. 2014;108(11):1677-87. doi:10.1016/j.rmed.2014.09.021.

24. Diel R, Vandeputte J, de Vries G, Stillo J, Wanlin M, Nienhaus A. Costs of tuberculosis disease in the European Union: a systematic analysis and cost calculation. Eur Respir J. 2014;43(2):554-65.

25. White VL, Moore-Gillon J. Resource implications of patients with multidrug resistant tuberculosis. Thorax. 2000;55(11):962-3.

26. Rajeswari R, Balasubramanian R, Muniyandi M, Geetharamani S, Thresa X Venkatesan P. Socio-economic impact of tuberculosis on patients and family in India. Int J Tuberc Lung Dis. 1999;3(10):869-77.

27. Peabody JW, Shimkhada R, Tan C, Luck J. The burden of disease, economic costs and clinical consequences of tuberculosis in the Philippines. Health Policy Plan. 2005;20(6):347-53. 
28. Atif M, Sulaiman SAS, Shafie AA, Asif M, Babar Z. Resource utilization pattern and cost of tuberculosis treatment from the provider and patient perspectives in the state of Penang. BMC Health Serv Res, Malaysia. 2014;14: 353. doi:10.1186/1472-6963-14-353.

29. Mauch V, Woods N, Kirubi B, Kipruto H, Sitienei J, Klinkenberg E. Assessing access barriers to tuberculosis care with the tool to Estimate Patients' Costs: pilot results from two districts in Kenya. BMC Public Health. 2011;11:43. doi:10.1186/1471-2458-11-43.

30. Umar NA, Fordham R, Abubakar I, Bachmann M. The indirect cost due to pulmonary Tuberculosis in patients receiving treatment in Bauchi State-Nigeria. Cost Effectiveness and Resource Allocation. Cost Eff Resour Alloc. 2012;10(1):6. doi:10.1186/1478-7547-10-6.

31. Foster N, Vassall A, Cleary S, Cunnama L, Churchyard G, Sinanovic E. The economic burden of TB diagnosis and treatment in South Africa. Soc Sci Med. 2015;130:42-50. doi:10.1016/j.socscimed.2015.01.046.

32. $\mathrm{WHO}$. WHO guide to identifying the economic consequences of disease and injury. Geneva: WHO; 2009

33. Nattrass N, Wakefold J, Muradzikwa S. Macroeconomics: theory and policy in South Africa. David Philip: Cape Town; 1997.

34. Dornbusch R, Fischer S, Mohr P, Rogers C. Macroeconomics. Cape Town: Lexicon Publishers; 1987.

35. World Bank Database. World Development Indicators. Washington, D.C. URL: http://data.worldbank.org/indicator/NV.AGR.TOTL.ZS/ countries?display=default Accessed on 15 January 2016 at 11 AM.

36. Chisholm D, Stanciole A, Edejer TT, Evans DB. Economic impact of disease and injury: counting what matters. BMJ. 2010;340:c924. doi:10.1136/bmj.c924.

37. Kirigia JM, Masiye F, Kirigia DG, Akweongo. Indirect costs associated with deaths from the Ebola virus disease in West Africa. Infect Dis Poverty. 2015; 4:45. doi:10.1186/s40249-015-0079-4.

38. Kirigia JM. Economic Evaluation of Public Health Problems in sub-Saharan Africa. Nairobi: University of Nairobi Press; 2009.

39. Drummond MF, Stoddart GL, Torrance GW. Methods for the economic evaluation of health care programmes. Oxford: Oxford University Press; 1988.

40. Curry S, Weiss J. Project analysis in developing countries. London: The MacMillan Press LTD; 1993.

41. Kirigia JM, Muthuri RKD, Orem JN, Kirigia DG. Counting the cost of child mortality in the World Health Organization African Region. BMC Public Health. 2015;15:1103. doi:10.1186/s12889-015-2465-z.

42. Kirigia JM, Sambo HB, Sambo LG, Barry SP. Economic burden of diabetes mellitus in the WHO African region. BMC Int Health Hum Rights. 2009;9:6. doi:10.1186/1472-698X-9-6.

43. WHO. Mortality and burden of disease estimates for WHO member states in 2008. Geneva: WHO; 2011.

44. Murray CJL. Rethinking DALYs. In: Murray CJL, Lopez AD, editors. The global burden of disease - a comprehensive assessment of mortality and disability from diseases, injuries, and risk factors in 1990 and projected to 2020 Cambridge: Harvard University Press; 1996. p. 1-98.

45. WHO. World Health Report 2000: health systems: improving performance. Geneva: WHO; 2000.

46. International Labour Organization (ILO). C138 - Minimum Age Convention, 1973 (No. 138). Geneva: ILO; 1973.

47. International Monetary Fund (IMF) website. World Economic Outlook Database. Washington, D.C. October 2015. URL: http://www.imf.org/ external/pubs/ft/weo/2015/02/weodata/weorept.aspx? Accessed on 20 January 2016 at 11 h30

48. Hickson KJ. The value of tuberculosis elimination and of progress in tuberculosis control in twentieth-century England and Wales. Int J Tuberc Lung Dis. 2009;13(9):1061-7.

49. United Nations. Transforming our world: the 2030 agenda for sustainable development. New York: UN; 2015.

50. WHO. Sixty-seventh World Health Assembly resolution WHA67.1 - Global Strategy and targets for tuberculosis prevention, care and control after 2015. Geneva: WHO; 2014

51. WHO. The End TB Strategy. Geneva: WHO; 2015.

52. Korenromp EL, Glaziou P, Fitzpatrick C, Floyd K, Hosseini M, Raviglione M, Atun R, Williams B. Implementing the global plan to stop TB, 2011-2015 - optimizing allocations and the Global Fund's contribution: a scenario projections study. PLoS One. 2012;7(6), e38816. doi:10.1371/journal.pone.0038816.

53. Organization of African Unity (OAU). Abuja declaration on HIV/AIDS, tuberculosis and other related infectious diseases. African summit on HIV/
AIDS, tuberculosis and other related infectious diseases Abuja, Nigeria 24-27, April 2001. Document OAU/SPS/ABUJA/3. Addis Ababa: OAU; 2001.

54. African Union. Assembly of the Union Nineteenth Ordinary Session declaration - Assembly/AU/Decl.2 (XIX). Declaration on the Report of AIDS Watch Africa (AWA) Action Committee of Heads of State and Government. Assembly of the Union Nineteenth Ordinary Session 15-16 July 2012. Addis Ababa, ETHIOPIA. Addis Ababa: AU; 2012.

55. African Union (AU). Abuja actions toward the elimination of HIV and AIDS, tuberculosis and malaria in Africa by 2030. Declaration of the special summit of African Union on HIV/AIDS, tuberculosis and malaria. Special Summit of African Union on HIV and AIDS, Tuberculosis and Malaria (ATM) Abuja, Nigeria 12-16 July 2013. Addis Ababa: AU; 2013.

56. AU. Assembly of the Union Twenty-Fifth Ordinary Session decision Assembly/AU/Dec.571(XXV) - Decision on the report of the AIDS watch Africa (AWA). Addis Ababa: AU; 2015

57. WHO/AFRO. Fifty-third WHO Regional Committee for Africa Resolution AFR/ RC53/R6 - Scaling up interventions against HIV/AIDS, tuberculosis and malaria in the WHO African Region. Brazzaville: WHO/AFRO; 2003.

58. WHO/AFRO. Fifty-fifth WHO Regional Committee for Africa resolution AFR/ RC55/R5 - Tuberculosis control: the situation in the African Region. Brazzaville: WHO/AFRO; 2005

59. WHO/AFRO. Fifty-ninth WHO Regional Committee for Africa resolution AFR/ RC59/R2 - Drug resistance related to AIDS, tuberculosis and malaria: issues, challenges and the way forward. Brazzaville: WHO/AFRO; 2009.

60. WHO/AFRO. Fifty-ninth WHO Regional Committee for Africa resolution AFR/ RC59/R7 - call for intensified action for HIV prevention and tuberculosis/HIV co-infection control in the African Region. Brazzaville: WHO/AFRO; 2009.

61. WHO. Sixty-eighty World Health Assembly resolution WHA68.7 - Global action plan on antimicrobial resistance. Geneva: WHO; 2016.

62. WHO. Sixty-Second World Health Assembly resolution WHA62.15 Prevention and Control of Multidrug-resistant TB and Extensively drugresistant TB. Geneva: WHO; 2009.

63. WHO. Fifty-eighth World Health Assembly resolution WHA58.14 Sustainable financing for tuberculosis prevention and control. Geneva: WHO; 2005

64. WHO. Fifty-eighth World Health Assembly resolution WHA58.27 - Improving the containment of antimicrobial resistance. Geneva: WHO; 2005.

65. UN. General Assembly resolution A/RES/70/1 - Transforming our world: the 2030 Agenda for Sustainable Development. New York: UN; 2015.

66. UN. General Assembly resolution A/RES/55/2 - United Nations Millennium Declaration. New York: UN; 2000.

67. OECD. OECD Framework for Statistics on the Distribution of Household Income, Consumption and Wealth. Paris: OECD Publishing; 2013.

68. Cowen T, Tabarrok A. Modern Principles of Macroeconomics. New York: Worth Publishers; 2009.

69. Stiglitz JE, Sen A, Fitoussi J-P. Mismeasuring our lives: why GDP doesn't add up. The report by the Commission on the Measurement of Economic Performance and Progress. London: The New Press; 2010.

70. WHO. International health regulations (2005). 2nd ed. Geneva: WHO; 2008.

71. Spellberg B, Guidos R, Gilbert D, Bradley J, Boucher HW, Scheld WM, Bartlett JG, Edwards J. The Epidemic of Antibiotic-Resistant Infections: A Call to Action for the Medical Community from the Infectious Diseases Society of America. Clin Infect Dis. 2008;46(2):155-64. doi:10.1086/524891.

72. Donald PR, van Helden PD. The Global Burden of Tuberculosis Combating Drug Resistance in Difficult Times. N Engl J Med. 2009;360(23): 2393-5. doi:10.1056/NEJMp0903806.

73. Akachi $Y$, Zumla A, Atun R. Investing in improved performance of national tuberculosis programmes reduces the tuberculosis burden: analysis of 22 high-burden countries, 2002-2009. J Infect Dis. 2012;205 Suppl 2:S284-92. doi:10.1093/infdis/jis189.

74. UN. Universal Declaration of Human Rights. New York: UN; 1948. 